\title{
Gamma oscillations in the somatosensory thalamus of a patient with a phantom limb: case report
}

\author{
Diellor Basha, MSc, ${ }^{1,4}$ Jonathan O. Dostrovsky, PhD, ${ }^{1,3,4}$ Suneil K. Kalia, MD, PhD, FRCSC, ${ }^{2-4}$ \\ Mojgan Hodaie, MD, MSc, FRCSC, ${ }^{2-4}$ Andres M. Lozano, MD, PhD, FRCSC, ${ }^{2-4}$ and \\ William D. Hutchison, $\mathrm{PhD}^{1,3,4}$
}

Departments of ${ }^{1}$ Physiology and ${ }^{2}$ Surgery, University of Toronto; ${ }^{3}$ Division of Neurosurgery, Toronto Western Hospital; and ${ }^{4}$ Krembil Western Research Institute, Toronto, Ontario, Canada

\begin{abstract}
The amputation of an extremity is commonly followed by phantom sensations that are perceived to originate from the missing limb. The mechanism underlying the generation of these sensations is still not clear although the development of abnormal oscillatory bursting in thalamic neurons may be involved. The theory of thalamocortical dysrhythmia implicates gamma oscillations in phantom pathophysiology although this rhythm has not been previously observed in the phantom limb thalamus. In this study, the authors report the novel observation of widespread 38-Hz gamma oscillatory activity in spike and local field potential recordings obtained from the ventral caudal somatosensory nucleus of the thalamus (Vc) of a phantom limb patient undergoing deep brain stimulation (DBS) surgery. Interestingly, microstimulation near tonically firing cells in the Vc resulted in high-frequency, gamma oscillatory discharges coincident with phantom sensations reported by the patient. Recordings from the somatosensory thalamus of comparator groups (essential tremor and pain) did not reveal the presence of gamma oscillatory activity.
\end{abstract}

https://thejns.org/doi/abs/10.3171/2017.5.JNS17170

KEY WORDS gamma oscillations; phantom limb; ventral caudal nucleus; somatosensory thalamus; microelectrode recordings; deep brain stimulation; functional neurosurgery; pain

$\mathrm{U}$ $P$ to $80 \%$ of amputees experience vivid sensations that are perceived to originate from the missing limb. ${ }^{24}$ In addition to innocuous phantom percepts, phantom limbs are often painful and lead to considerable distress. ${ }^{31}$ Deep brain stimulation (DBS) of the ventral caudal somatosensory nucleus of the thalamus $(\mathrm{Vc})$ can ameliorate phantom pain, ${ }^{3,11,39}$ although the mechanisms underlying DBS effects or the generation of the phantom percepts remain poorly understood. Experimentally, it is possible to elicit phantom percepts by microstimulation within the Vc even many years after the loss of a limb, ${ }^{5}$ and phantom movements of the missing limb may elicit responses from neurons in several thalamic nuclei, including the Vc and the ventral intermediate nucleus of the cerebellar thalamus (Vim). ${ }^{1}$ The presence of these projected and receptive fields suggests that the thalamocortical representation of the missing limb persists for a long time after the amputation. The severity of phantom pain has recently been shown to correlate with the maintained cortical representation of the former limb area, ${ }^{22}$ however, it is still unclear what leads to the spontaneous activation of the phantom limb representation and how this activation generates the phantom percept.

Thalamic relay neurons of the somatosensory nucleus receive peripheral input from ascending fibers of the dorsal column-medial lemniscal pathway and send projections to Layer IV interneurons of the primary somatosensory cortex. Re-entrant input from Layer VI pyramidal neurons directly excites relay cells and indirectly inhibits them by driving the inhibitory action of the thalamic re-

ABBREVIATIONS AC = anterior commissure; $\mathrm{DBS}=$ deep brain stimulation; $\mathrm{ET}=$ essential tremor; $\mathrm{LFP}=$ local field potential; $\mathrm{PC}=$ posterior commissure; $\mathrm{PSD}=$ power spectrum density; $V \mathrm{C}=$ ventral caudal somatosensory nucleus of the thalamus; Vim = ventral intermediate nucleus of the cerebellar thalamus; Vop $=$ ventral oral posterior nucleus of the thalamus.

SUBMITTED January 18, 2017. ACCEPTED May 8, 2017.

INCLUDE WHEN CITING Published online November 10, 2017; DOI: 10.3171/2017.5.JNS17170. 
ticular nucleus (reviewed in Jones 2002 ${ }^{14}$ ). Upon depolarization by sensory input, relay cells fire when in the tonic mode $8,27,40$ in a manner that reflects the afferent sensory input. When hyperpolarized, relay neurons switch to lowfrequency (approximately 5-Hz) burst-firing mode ${ }^{12}$ where sensory input is not effectively relayed. ${ }^{23}$ These bursts, called low-threshold spike bursts, are generated by a Ttype calcium channel that is activated under hyperpolarizing conditions and frequently fire rhythmically at $5 \mathrm{~Hz}$. However, under partial depolarization, relay cells exhibit $40-\mathrm{Hz}$ subthreshold oscillations that predispose them to burst firing at gamma frequency $(40 \mathrm{~Hz}){ }^{32}$ Corticothalamic discharges of high frequency can exacerbate this subthreshold oscillation, shifting the firing mode of the relay neuron from tonic to $40-\mathrm{Hz}$ oscillatory firing and thus generating gamma resonance within the thalamocortical loop. ${ }^{7,20}$ The binding-by-synchrony theory ${ }^{9,13,37}$ asserts that such widespread gamma oscillations support perception by temporally binding the disparate thalamocortical representations of a percept into a coherent whole.

More recently, a distinction has been drawn between physiological gamma oscillations and those that arise pathologically following peripheral injury or central dysfunction. ${ }^{30}$ Tinnitus, the auditory analog of somatic phantom perception, ${ }^{6}$ has been linked to pathological changes in the rhythmicity of thalamic neurons. ${ }^{21}$ Following otological injury, the deafferented thalamus switches to burstmode firing at delta/theta $(4-8 \mathrm{~Hz})$ frequencies because of local hyperpolarization. Thalamic delta/theta synchrony is thought to elicit "edge effect" gamma oscillatory activity in the cortex by reducing lateral inhibition and thus disinhibiting the endogenous cortical propensity for gamma oscillatory activity. ${ }^{18}$ It is thought that increased gamma activity pathologically activates the thalamocortical representation of a tone, causing the patient to experience persistent ringing or noise (auditory phantom). ${ }^{36}$ Apart from tinnitus studies, however, there have been very few investigations of this process in phantom limb sensation. Some studies have reported increased cortical gamma oscillations in neuropathic pain, ${ }^{10,15,29}$ although it is unclear how these findings relate specifically to phantom limb disorder and dysrhythmia of the thalamus. To the best of our knowledge, gamma oscillations in the principal somatosensory thalamus of an awake phantom limb patient have not been previously described.

\section{Case Report}

Summary

Recordings were collected from 1 patient with phantom limb pain (a 42-year-old man), 4 patients with neuropathic pain, and 5 patients with essential tremor (ET) during microelectrode-guided mapping of the thalamus for DBS surgery. Recordings were obtained while the patients were awake under local scalp anesthesia and withdrawn from all medications 12 hours prior to surgery. The preoperative clinical assessments of pain were performed by a neurologist at Toronto Western Hospital using a descriptive and numeric pain rating scale that assessed pain intensity and distress levels. Patients with other types of neuropathic pain ( 3 post-stroke and 1 spinal injury) and ET patients, who served as comparator groups to phantom limb, had no symptoms or medical history of phantom pain or innocuous phantom percepts. All patients gave informed written consent for participation in the study, which was reviewed and approved by the University Health Network Ethical Review Board at the University of Toronto.

\section{History and Presentation}

Twelve years prior to surgery, the patient with a phantom limb sustained a traumatic amputation of the right arm at the level of the shoulder joint, which led to the development of severe neuropathic pain within the stump and in the phantom arm, with greatest pain intensity in the phantom hand and the dorsal surface of the phantom forearm. The pain was characterized by the patient as severe, rated numerically at $7 / 10$ and described by the patient using the words "burning/throbbing" and "dreadful/horrible." The pain was predominantly in the phantom hand, radiating into the arm and becoming worse with left head tilt, with less intense pain in the shoulder stump. The patient did not feel that his phantom arm was telescoped, although he felt it was fixed in a specific position that he was unable to manipulate. In the 12 years following the amputation, the patient underwent two resections of stump neuromas that relieved stump pain temporarily (7.8 to $1-2 / 10$ ) although pain in the phantom limb became progressively worse over time. During the electrophysiological mapping of the left ventral thalamus, microstimulation within the Vc region evoked paresthesia in the phantom arm as well as in the shoulder stump (see Pathological Findings below). The pain improved to 4-5/10 following the implantation of DBS electrodes (insertional effect, see Hamani et al. ${ }^{11}$ ) with a further improvement to 2-3/10 upon activation of the stimulator $(130 \mathrm{~Hz}, 1.3 \mathrm{~V})$. Therapeutic DBS did not induce paresthesia in the phantom limb or elsewhere on the body.

\section{Microelectrode Recordings}

Detailed descriptions of the intraoperative techniques used in this study have been previously published. ${ }^{16,34}$ Briefly, physiological exploration of the thalamus was performed with dual microelectrodes under local anesthetic after the determination of stereotactic targets by MRI. The stereotactic coordinates of the anterior commissure (AC) and posterior commissure (PC) were first determined by 1.5-T MRI and were used to estimate the location of the ventral thalamic nuclear group based on the $14.5-\mathrm{mm}$ sagittal section of the standard atlas of Schaltenbrand and Wahren. ${ }^{28}$ The target for Vim in the patients with ET was $\mathrm{x}=14.5 \mathrm{~mm}$ from the midline or $\mathrm{x}=11 \mathrm{~mm}$ from the lateral wall of third ventricle, $y=5-6 \mathrm{~mm}$ anterior to $\mathrm{PC}$, and $\mathrm{z}=0-2 \mathrm{~mm}$ below the AC-PC line. The target for the $\mathrm{Vc}$ in the patients with pain was $\mathrm{x}=14.5 \mathrm{~mm}$ from midline, $\mathrm{y}=2-3 \mathrm{~mm}$ anterior to $\mathrm{PC}$, and $\mathrm{z}=0-2 \mathrm{~mm}$ below the AC-PC line.

Physiological identification of the ventral thalamic nuclei was performed using single-unit recordings obtained from two microelectrodes (about 25- $\mu \mathrm{m}$ tip length, axes offset by $600 \mu \mathrm{m}$ in the mediolateral axis, about $0.2-\mathrm{M} \Omega$ impedance at $1000 \mathrm{~Hz}$ ) that traversed the thalamus in an anterodorsal to ventroposterior direction, and by using 

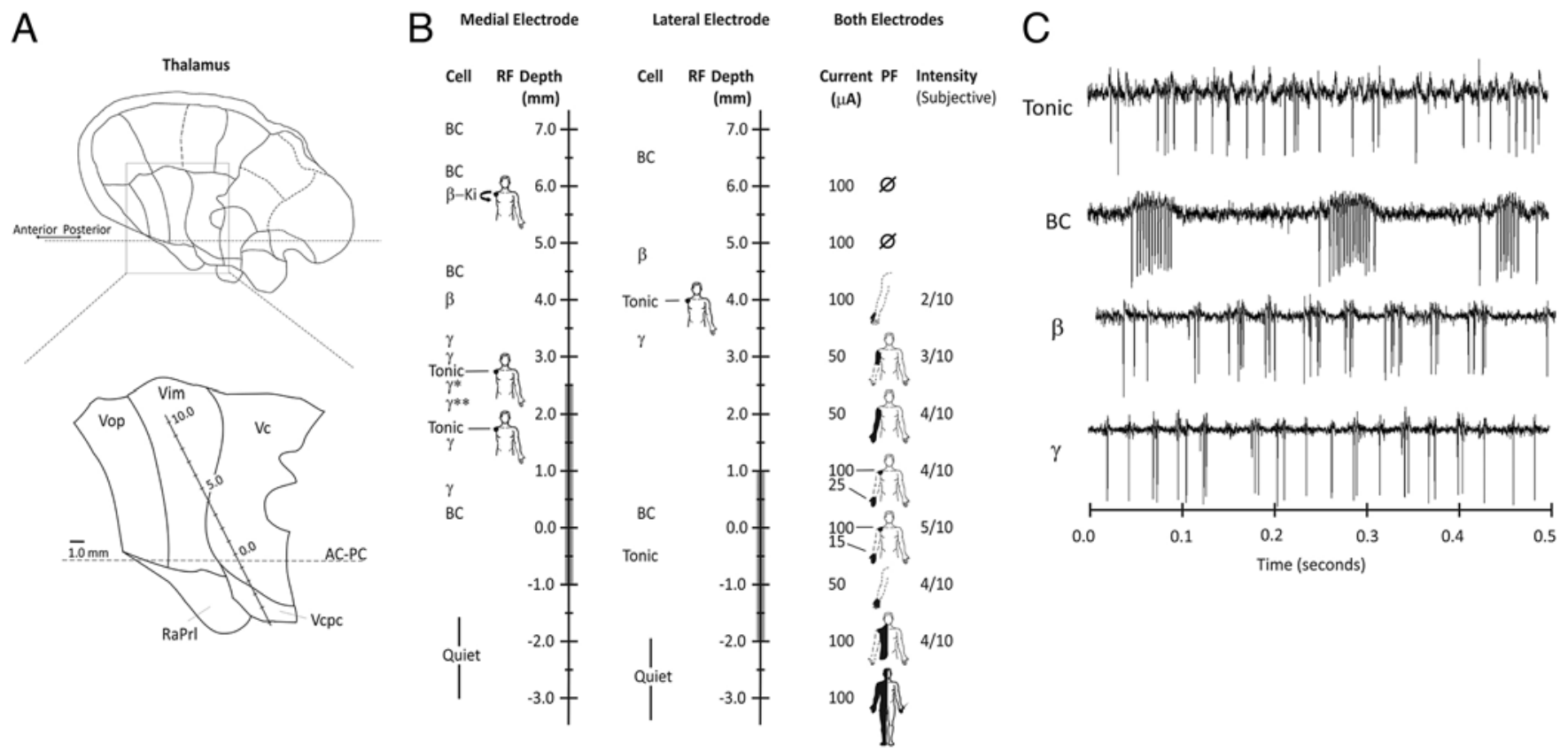

\begin{abstract}
FIG. 1. Physiological observations in the phantom limb patient, recorded during microelectrode-guided mapping of the left ventral thalamus. A: The thalamic area explored in the study, depicted on a sagittal section of the Schaltenbrand and Wahren map of the thalamus, $14.5 \mathrm{~mm}$ lateral to midline. The microelectrode trajectory was calculated according to radiologically determined stereotactic coordinates of the intercommissural line (AC-PC). B: Physiological effects observed along the trajectory of the medial and the lateral electrodes. The leftmost columns for each electrode indicate the observed cell types and their corresponding receptive fields (RFs). The columns to the right of the depth profile show the threshold stimulation intensities that produced paresthesia in the corresponding projected field (PF) and the patient's rating of the intensity of the evoked paresthesia. Microstimulation was performed simultaneously from both electrodes. The intensity of the perceived projected field as reported by the patient is shown in the rightmost column. null symbol = no effect. C: Sample recording segments showing the characteristic firing pattern of each cell type observed along the trajectory. $\beta=$ beta oscillatory cell; $\gamma=$ gamma oscillatory cell; $\gamma^{*}=$ shown in Fig. $3 ; \gamma^{* *}=$ shown in Fig. $4 ; \mathrm{BC}=$ bursting cell; $\mathrm{Ki}=$ kinaesthetic response; $\mathrm{RaPrl}=$ prelemniscal radiation; $\mathrm{Vcpc}=$ ventral caudal parvocellular.
\end{abstract}

microstimulation through the recording electrodes. Along the progression of the microelectrode trajectory, single units were tested for responses to limb movements and peripheral tactile stimulation and their receptive fields were recorded. Single units that responded to hand, arm, leg, or stump movement were considered to be part of the motor thalamus (Vim, or ventral oral posterior [Vop]). Single units that responded to tactile stimulation of the hand, arm (ET and central pain), leg, or stump were considered to be part of the Vc.

Additionally, microstimulation (monopolar, biphasic, 3-100 $\mu \mathrm{A}, 200 \mathrm{~Hz}, 1 \mathrm{sec}$ duration trains; pulse width 0.15 msec cathodal, 0.15 msec anodal) was conducted every millimeter along the trajectory of the microelectrode and any stimulation-induced effects (projected sensory fields or tremor reduction in ET) were noted (Fig. 1A and B). The first site in the trajectory where microstimulation induced paresthesia was considered to be the anterior border of the Vc. A high threshold for the induction of focal paresthesia $(>50 \mu \mathrm{A})$ was considered to indicate the $\mathrm{Vim} / \mathrm{Vc}$ border area whereas a low threshold $(<50 \mu \mathrm{A})$ was considered to indicate a site within the Vc. High-intensity stimulation $(>50 \mu \mathrm{A})$ that induced general hemibody paresthesia was considered to indicate stimulation of lemniscal fibers. The pre- and poststimulation period was recorded to examine the effects of microstimulation on the firing properties of Vc cells.

\section{Analysis}

Spike times and local field potential (LFP) data were obtained continuously during the dorsoventral/anteroposterior progression of the microelectrodes. To construct a spectral profile of the trajectory in the phantom limb patient (Fig. 2), a series of recording segments (mean duration $18.6 \pm 4.3$ seconds) were obtained from equally spaced locations along the trajectory of the microelectrode (3 samples per millimeter, spanning from $7 \mathrm{~mm}$ above the target to $3 \mathrm{~mm}$ below the target). The LFP data from each segment were then bandpass filtered (13-45 $\mathrm{Hz}$ ) using a digital infinite impulse response filter, and these segments were merged into 1 continuous data file that was displayed as a waterfall plot consisting of 100 slices (Fig. 2). To analyze the spectral content of Vc spike trains, single-unit activity was first discriminated using the "wavemark" template matching tool in Spike2 (Cambridge Electronic Design, Ltd.) and the discrete Fourier transform was obtained using in-house programs (Fig. 3 ). Single units with significant oscillatory peaks in the gamma and/or beta bands were counted and expressed as a percentage of the total sample (see Weinberger et al. ${ }^{38}$ for 


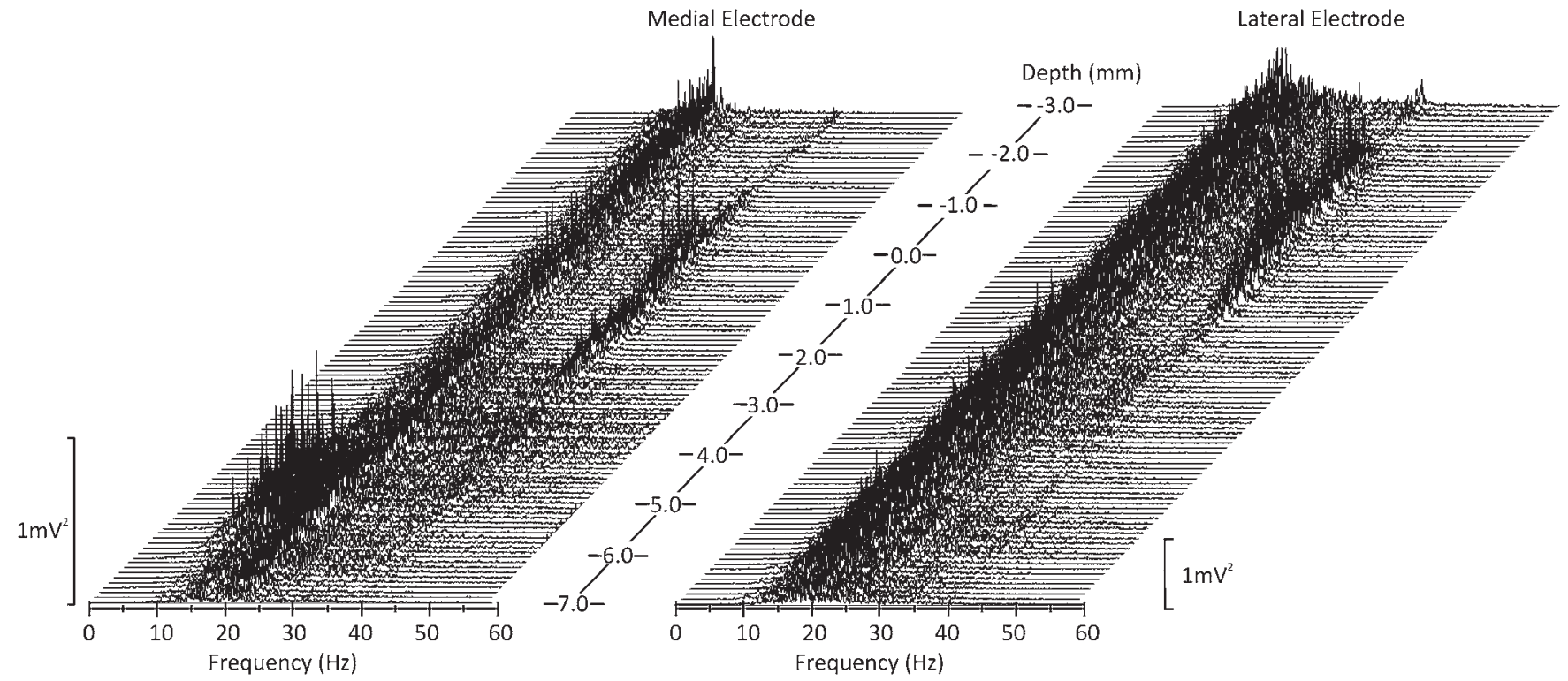

FIG. 2. Spectral profile of LFP recording segments (bandpassed $13-45 \mathrm{~Hz}$ ) collected along the lateral and medial microelectrode trajectories in the phantom limb patient. Note the prominent gamma band $(38 \mathrm{~Hz})$ spanning depths that correspond to the Vc. Locations anterodorsal to the sensory thalamus (depth $>4.0 \mathrm{~mm}$ ) were characterized by beta oscillations that are idiosyncratic to the motor thalamus (Basha et al. ${ }^{2}$ ).

a similar procedure). The average patient-specific power spectrum density (PSD) of Vc single units was calculated by obtaining the mean PSD of all the single units recorded from each patient (Fig. 4). The mean PSD of the phantom limb patient was then compared against the mean PSD of each patient with ET or pain (Fig. 4). For comparison of LFP spectral properties across patients, the area under the curve of the LFP spectrogram was calculated and used as a measure of spectral power according to methods described previously. ${ }^{2}$

\section{Pathological Findings}

Single-unit and LFP activity was recorded from 19 ventral thalamic sites in the patient with the phantom limb. Of the 19 single-unit recordings from the 2 microelectrodes, 11 were ventroposterior to the first site of stimulation-induced paresthesia (anterior Vc border) and were considered to be Vc cells (Fig. 1A and B). Of these 11 cells, 3 responded to tactile stimulation of the stump (shoulder receptive field). Of the 8 cells that were recorded dorsoanterior to the anterior border of the $\mathrm{Vc}, 2$ were responsive to movements of the stump (shoulder rotation), characteristic of the motor thalamus. In contrast to our findings mapping the $\mathrm{Vc}$ in previous patients, the firing pattern of 7 of the $11 \mathrm{Vc}$ cells in the phantom limb patient had significant narrow-band gamma oscillations (Fig. 1C) although none of these 7 gamma oscillatory cells were responsive to tactile stimulation of the stump. By comparison, the $\mathrm{Vc}$ cells from patients with ET and pain were not significantly oscillatory at any frequency band (Fig. 4). Only 1 (4.5\%) of the $22 \mathrm{Vc}$ neurons recorded from the patients with ET fired at gamma frequency (43 Hz peak) and $1(5 \%)$ of the $20 \mathrm{Vc}$ neurons recorded from the patient with neuropathic pain fired at gamma frequency (36 Hz peak). Similarly,
LFP power over the gamma peak $(38 \mathrm{~Hz})$ was significantly higher in the phantom limb patient in comparison with the ET and pain patient groups $(\mathrm{p}<0.01, \mathrm{t}$-test).

Spectral analysis of the LFP along the length of the microelectrode trajectory revealed a prominent increase in the power of gamma oscillation at $38 \mathrm{~Hz}$ in the region corresponding to the Vc (Fig. 2). In LFP recordings obtained from the medial electrode, the increase in gamma power was observed over a 4-mm span (from $3 \mathrm{~mm}$ above to $1 \mathrm{~mm}$ below the target). In LFP recordings obtained from the lateral electrode, the gamma oscillation spanned the region from $1 \mathrm{~mm}$ above to $-2 \mathrm{~mm}$ below target. The segment of the microelectrode trajectory where tactile-responsive single units (stump-receptive fields) were located and where microstimulation-induced paresthesia was observed spanned from $4 \mathrm{~mm}$ above to $1 \mathrm{~mm}$ below target. Lowest thresholds and smallest projected fields were from $1 \mathrm{~mm}$ above to $1 \mathrm{~mm}$ below the target.

Coherence analysis of $\mathrm{Vc}$ recordings showed significant linear dependency between spike occurrences and LFP data, maximal coherence at $38 \mathrm{~Hz}$, with spikes occurring on the rising (negative-going) phase of the gamma cycle (Fig. 3).

Microstimulation near 3 nonoscillatory Vc cells resulted in a period of sustained gamma oscillatory firing that outlasted the stimulation-induced phantom sensation (paresthesia) by 15 seconds (Fig. 5). The instantaneous frequency of the spikes ranged from 40 to $200 \mathrm{~Hz}$ (Fig. 5D) following stimulation and gradually decreased to a $30-\mathrm{Hz}$ plateau before resuming the prestimulation firing rate (20-second mark, Fig. 5D). Spectral analysis of spike times showed that the cell maintained gamma oscillatory firing during the gradual decrease in instantaneous frequency but resumed prestimulation nonoscillatory firing once the 

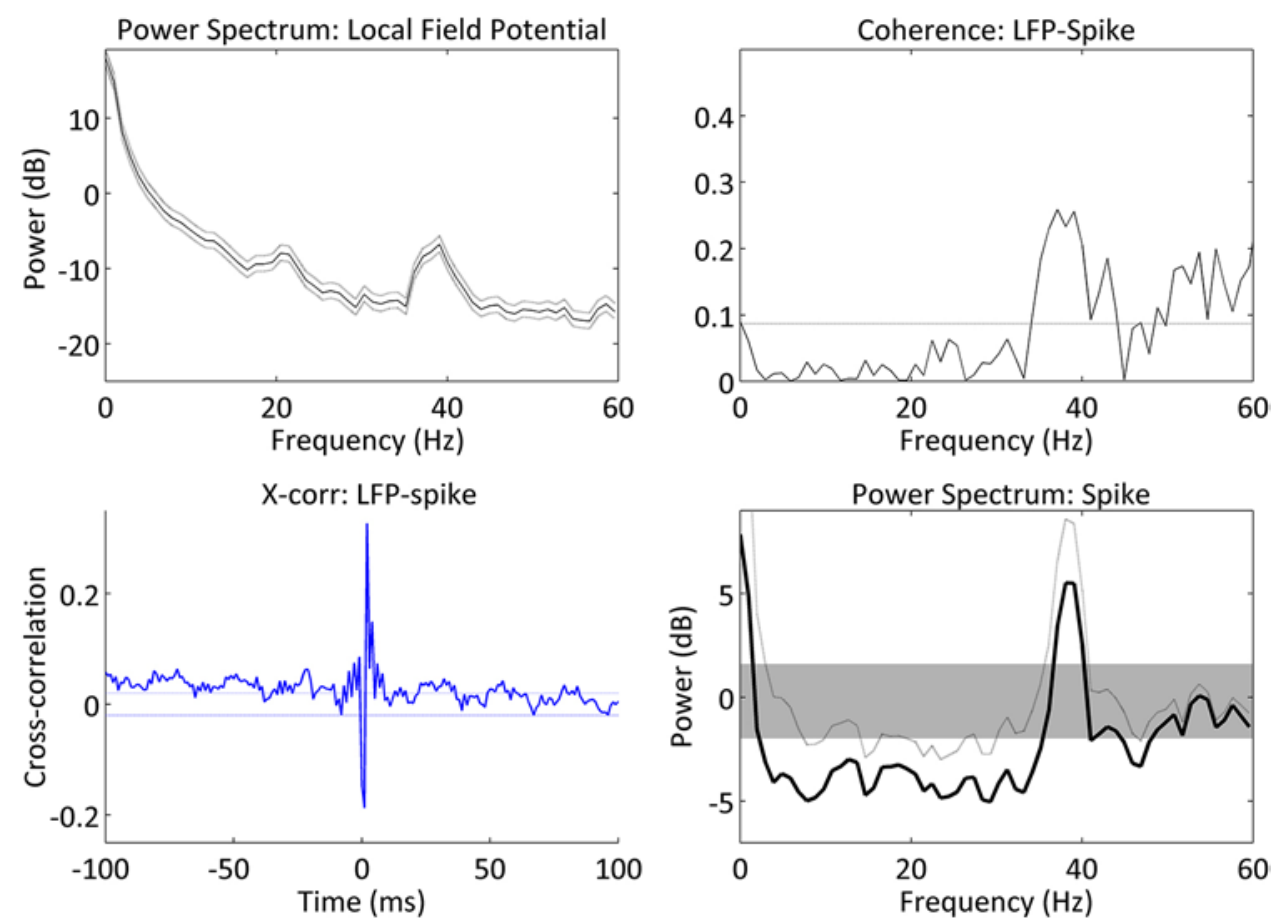

FIG. 3. Graphs of the timing relationship between spike and LFP oscillations recorded from the Vc of the phantom limb patient. Spike-LFP gamma oscillations were significantly coherent with the spike occurring on the rising phase of the LFP gamma cycle. The matrix depicts data recorded at a depth $2.5 \mathrm{~mm}$ above the target, as indicated by $\gamma^{*}$ in Fig. 1 . X-corr $=$ cross-correlation. Figure is available in color online only.

instantaneous frequency fell below $30 \mathrm{~Hz}$. Sham stimulation $(0 \mu \mathrm{A})$ did not change the firing properties of the cell, and the patient did not report any sensation. Microstimulation was conducted as part of the intraoperative mapping of the thalamus such that stimulation was delivered every millimeter to elicit the phantom percept. Stimulation near recorded cells was not conducted systematically and the 3 cells reported here were recorded and stimulated as part of the intraoperative mapping procedure.

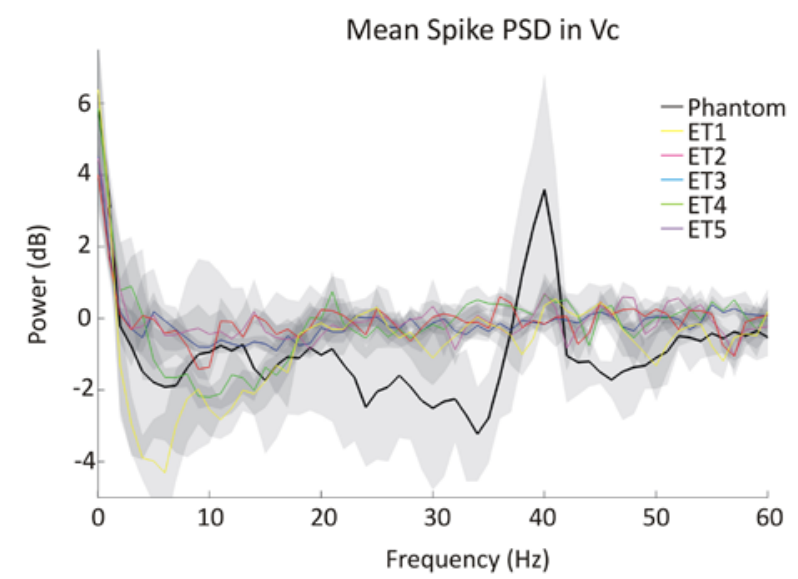

\section{Discussion}

\section{Gamma Oscillations in Deafferentation}

In this paper, we describe widespread spontaneous gamma activity in the Vc of a patient with a phantom limb. Microstimulation of $\mathrm{Vc}$ sites within the presumed representation of the amputated limb elicited the phantom percept and induced a shift in the firing pattern of the Vc neuron from tonic to $38 \mathrm{~Hz}$ gamma oscillatory activity that out-

FIG. 4. The mean spike spectrogram of all 11 recorded Vc cells in the phantom limb patient compared with mean spectra of $22 \mathrm{Vc}$ cells in 5 patients with ET (left) and 20 Vc cells in 4 patients with pain (right). Gamma oscillatory spike activity was significantly higher in the Vc of the phantom limb patient. Figure is available in color online only.

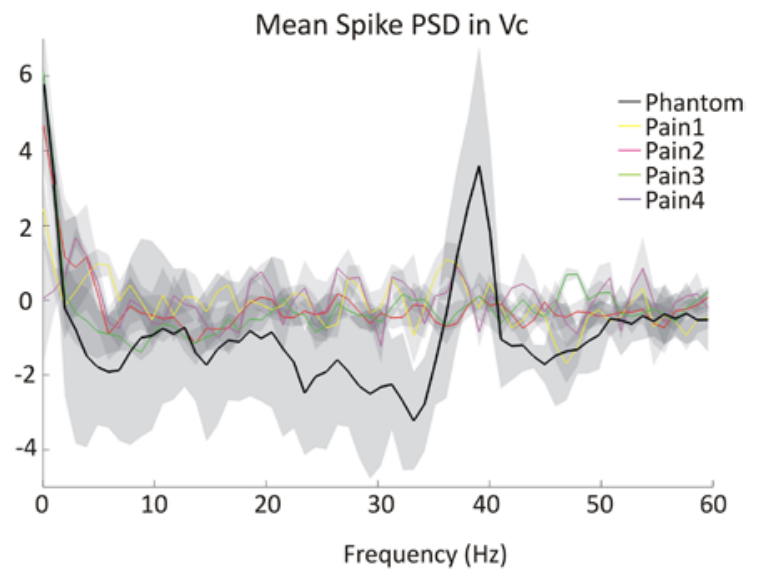




\begin{tabular}{cccccc} 
Non-oscillatory firing & $\uparrow$ & Gamma oscillatory firing $(38 \mathrm{~Hz})$ & & Non-oscillatory firing \\
\hline 0 & Microstimulation & 10 & 15 & 20 & 25
\end{tabular}

B

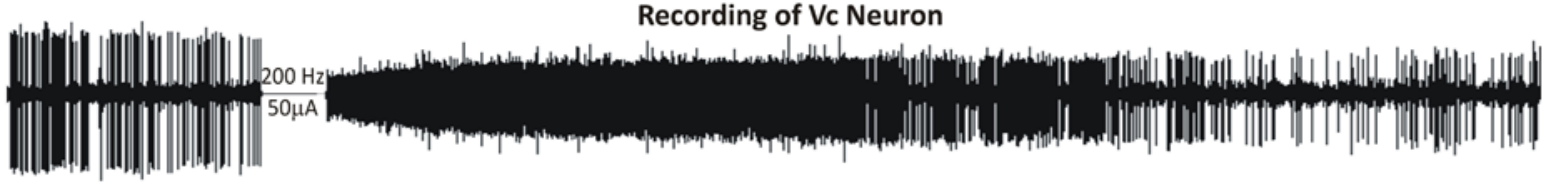

C Spike Raster

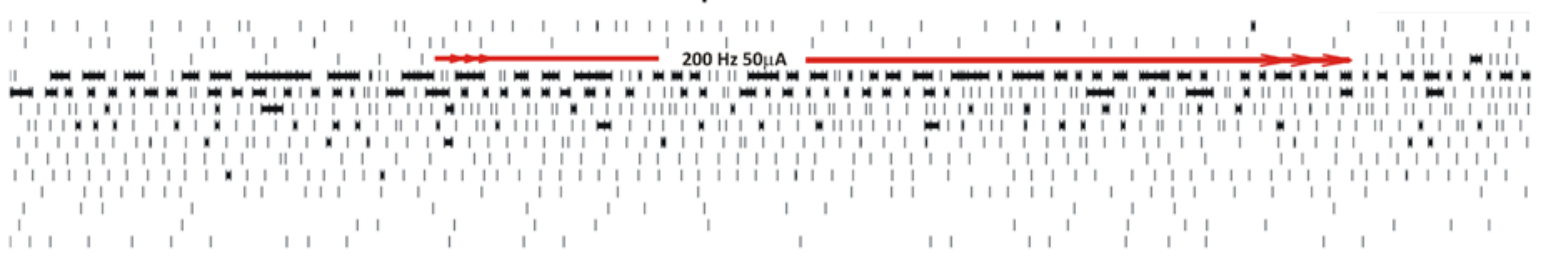

D

Instantaneous Frequency

$200 \mathrm{~ms}$
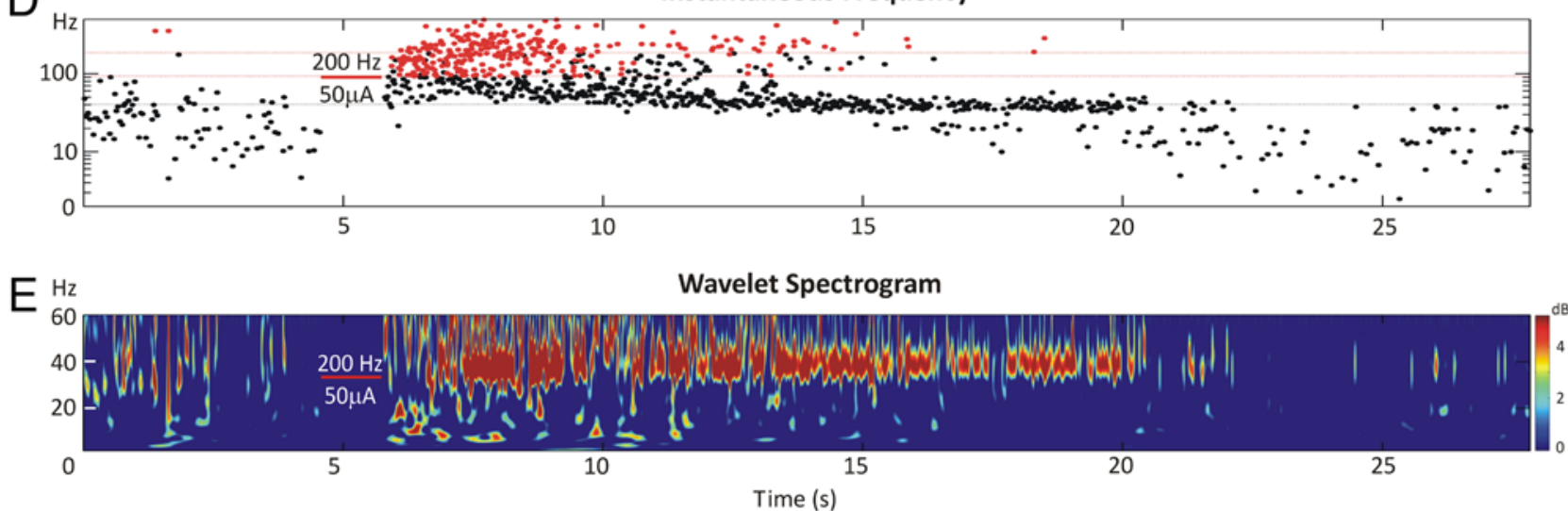

FIG. 5. High-frequency microstimulation in the Vc generated the phantom arm percept while simultaneously inducing gamma oscillatory firing in a Vc cell. A: Diagram of salient peri-stimulus events. B: High-pass filtered $(>350 \mathrm{~Hz})$ recording of Vc spiking activity before and after delivery of a 1-second, $50-\mu \mathrm{A}, 200-\mathrm{Hz}$ stimulus train of $30-\mathrm{msec}$ pulses. C: Spike raster showing the time of occurrence of each spike around the microstimulation. The start of recording is top left and each raster line is 2 seconds long. Spikes joined by a thick horizontal line represent spikes that contribute to a burst. D: Instantaneous frequency of the spike train (1/interspike interval) plotted on a log of frequency versus time axes. E: Wavelet spectrogram showing the frequency content of spiking activity. Prominent gamma oscillatory firing followed microstimulation. This unit was recorded at a depth of $2.0 \mathrm{~mm}$ above the target as indicated in Fig. 1 by $\gamma^{* *}$. Figure is available in color online only.

lasted the period of stimulation by about 15 seconds in all 3 of the recorded cells (Fig. 5). This prolonged discharge is indicative of poststimulus depolarization that was possibly facilitated by glutamatergic release from corticothalamic terminals. Interestingly, the gamma oscillatory firing persisted only during high firing rates and subsided abruptly as firing rate diminished (Fig. 5), consistent with the view that gamma oscillations are maintained under a state of excitatory input. In the immediate poststimulation period, the Vc cell fired at high and varied rates with a gamma oscillatory firing pattern. As the firing rate decreased, the gamma oscillation desynchronized (20-second mark, Fig. 5), suggesting a relationship between firing rate and gamma oscillatory discharges. Several studies have shown that a state of relative depolarization is a precondition for the emergence of gamma oscillations in thalamic sites. ${ }^{19,26,33,35}$ In an el- egant study, Crandall et al. ${ }^{4}$ recently demonstrated that the cortical influence on the thalamus is dynamic, switching between oscillatory modes that increase or decrease the excitability of the thalamic cell. In their study, endogenous corticothalamic gamma input increased the excitability of thalamic neurons and the efficacy of afferent sensory stimulation whereas low-frequency corticothalamic input suppressed thalamic excitability. The authors concluded that the cortex switches between these two modes of top-down control in a manner that regulates thalamic throughput. One possible explanation for the observed gamma oscillations in our study may involve such a "dynamic switch" whereby descending corticothalamic input entrains thalamic cells to gamma oscillatory firing. Recordings from the Vc of comparator groups (ET and pain) had no salient rhythms, suggesting that the gamma activity observed in 
Vc is related to the manifestation of phantom limb sensations.

\section{Gamma Oscillations in Perception}

The conscious experience of a phantom limb depends on a complex interplay between the somatosensory thalamus and cortical representations of the missing limb. Following amputation, the loss of peripheral input to the thalamus is believed to trigger abnormal rhythmic discharges that activate the representation of the missing limb within thalamocortical circuits. In the healthy human brain, transient rhythmic activity near $40 \mathrm{~Hz}$ relates to cognitive processing of sensory stimuli and may facilitate the temporal binding of sensory stimuli into a coherent conscious percept. In this paper we show the presence of gamma activity in the somatosensory thalamus of a phantom limb patient. The results are in agreement with other studies ${ }^{10,15,17,19,29}$ that have implicated oscillatory dysfunction in sensory disorders, although, to our knowledge, our study is the first to describe the narrowband gamma rhythm in the thalamus of an awake phantom limb patient. Furthermore, the results provide support for the view that aberrant rhythmogenesis in the thalamus underlies phantom perception and that $40-\mathrm{Hz}$ activity underlies sensory processing.

\section{Pitfalls}

This is a single case study and needs to be confirmed in a larger patient population; however, DBS surgeries for phantom limb are increasingly rare, as many patients are now treated with alternate therapy such as dorsal column stimulation. ${ }^{25}$ Due to the constraints of the operating room, we were unable to extract detailed characterizations of the percept and relied instead on the patient's verbal reports of phantom limb intensity based on a 1-10 rating scale. Such subjective ratings are often vulnerable to patient bias; however, we did implement sham stimulation at $0 \mu \mathrm{A}$ and the patient did not report any effects.

\section{Acknowledgments}

Research support was provided to Dr. Hutchison from the Canadian Institutes of Health Research MOP grant no. 98006.

\section{References}

1. Anderson WS, Weiss N, Lawson HC, Ohara S, Rowland L, Lenz FA: Demonstration of motor imagery movement and phantom movement-related neuronal activity in human thalamus. Neuroreport 22:88-92, 2011

2. Basha D, Dostrovsky JO, Lopez Rios AL, Hodaie M, Lozano AM, Hutchison WD: Beta oscillatory neurons in the motor thalamus of movement disorder and pain patients. Exp Neurol 261:782-790, 2014

3. Bittar RG, Otero S, Carter H, Aziz TZ: Deep brain stimulation for phantom limb pain. J Clin Neurosci 12:399-404, 2005

4. Crandall SR, Cruikshank SJ, Connors BW: A corticothalamic switch: controlling the thalamus with dynamic synapses. Neuron 86:768-782, 2015

5. Davis KD, Kiss ZH, Luo L, Tasker RR, Lozano AM, Dostrovsky JO: Phantom sensations generated by thalamic microstimulation. Nature 391:385-387, 1998

6. De Ridder D, Elgoyhen AB, Romo R, Langguth B: Phantom percepts: tinnitus and pain as persisting aversive memory networks. Proc Natl Acad Sci U S A 108:8075-8080, 2011

7. Destexhe A, Contreras D, Steriade M: Cortically-induced coherence of a thalamic-generated oscillation. Neuroscience 92:427-443, 1999

8. Destexhe A, Neubig M, Ulrich D, Huguenard J: Dendritic low-threshold calcium currents in thalamic relay cells. J Neurosci 18:3574-3588, 1998

9. Gray CM: The temporal correlation hypothesis of visual feature integration: still alive and well. Neuron 24:31-47, 1999

10. Gross J, Schnitzler A, Timmermann L, Ploner M: Gamma oscillations in human primary somatosensory cortex reflect pain perception. PLoS Biol 5:e133, 2007

11. Hamani C, Schwalb JM, Rezai AR, Dostrovsky JO, Davis KD, Lozano AM: Deep brain stimulation for chronic neuropathic pain: long-term outcome and the incidence of insertional effect. Pain 125:188-196, 2006

12. Jahnsen H, Llinás R: Electrophysiological properties of guinea-pig thalamic neurones: an in vitro study. J Physiol 349:205-226, 1984

13. Joliot M, Ribary U, Llinás R: Human oscillatory brain activity near $40 \mathrm{~Hz}$ coexists with cognitive temporal binding. Proc Natl Acad Sci U S A 91:11748-11751, 1994

14. Jones EG: Thalamic circuitry and thalamocortical synchrony Philos Trans R Soc Lond B Biol Sci 357:1659-1673, 2002

15. Kim JH, Chien JH, Liu CC, Lenz FA: Painful cutaneous laser stimuli induce event-related gamma-band activity in the lateral thalamus of humans. J Neurophysiol 113:1564-1573, 2015

16. Levy R, Lozano AM, Hutchison WD, Dostrovsky JO: Dual microelectrode technique for deep brain stereotactic surgery in humans. Neurosurgery 60 (4 Suppl 2):277-284, 2007

17. Llinás R, Ribary U, Jeanmonod D, Cancro R, Kronberg E, Schulman J, et al: Thalamocortical dysrhythmia I. Functional and imaging aspects. Thalamus Relat Syst 1:237-244, 2001

18. Llinás R, Urbano FJ, Leznik E, Ramírez RR, van Marle HJF: Rhythmic and dysrhythmic thalamocortical dynamics: GABA systems and the edge effect. Trends Neurosci 28:325-333, 2005

19. Llinás RR, Choi S, Urbano FJ, Shin HS: Gamma-band deficiency and abnormal thalamocortical activity in P/Q-type channel mutant mice. Proc Natl Acad Sci U S A 104:1781917824, 2007

20. Llinás RR, Leznik E, Urbano FJ: Temporal binding via cortical coincidence detection of specific and nonspecific thalamocortical inputs: a voltage-dependent dye-imaging study in mouse brain slices. Proc Natl Acad Sci U S A 99:449-454, 2002

21. Llinás RR, Ribary U, Jeanmonod D, Kronberg E, Mitra PP: Thalamocortical dysrhythmia: a neurological and neuropsychiatric syndrome characterized by magnetoencephalography. Proc Natl Acad Sci U S A 96:15222-15227, 1999

22. Makin TR, Scholz J, Filippini N, Henderson Slater D, Tracey I, Johansen-Berg H: Phantom pain is associated with preserved structure and function in the former hand area. Nat Commun 4:1570, 2013

23. McCormick DA, Feeser HR: Functional implications of burst firing and single spike activity in lateral geniculate relay neurons. Neuroscience 39:103-113, 1990

24. Nikolajsen L: Phantom limb, in McMahon S, Koltzenburg M, Tracey I, et al (eds): Wall and Melzack's Texbook of Pain, ed 6. Philadelphia: Elsevier Saunders, 2013, pp 915-918

25. Nizard J, Raoul S, Nguyen JP, Lefaucheur JP: Invasive stimulation therapies for the treatment of refractory pain. Discov Med 14:237-246, 2012

26. Pedroarena C, Llinás R: Dendritic calcium conductances generate high-frequency oscillation in thalamocortical neurons. Proc Natl Acad Sci U S A 94:724-728, 1997

27. Ramcharan EJ, Gnadt JW, Sherman SM: Burst and tonic fir- 
ing in thalamic cells of unanesthetized, behaving monkeys. Vis Neurosci 17:55-62, 2000

28. Schaltenbrand G, Wahren W: Atlas for Stereotaxy of the Human Brain. Stuttgart: Thieme, 1977

29. Schulz E, May ES, Postorino M, Tiemann L, Nickel MM, Witkovsky V, et al: Prefrontal gamma oscillations encode tonic pain in humans. Cereb Cortex 25:4407-4414, 2015

30. Sedley W, Cunningham MO: Do cortical gamma oscillations promote or suppress perception? An under-asked question with an over-assumed answer. Front Hum Neurosci 7:595, 2013

31. Sherman RA, Sherman CJ, Parker L: Chronic phantom and stump pain among American veterans: results of a survey. Pain 18:83-95, 1984

32. Steriade M, Amzica F: Intracortical and corticothalamic coherency of fast spontaneous oscillations. Proc Natl Acad Sci U S A 93:2533-2538, 1996

33. Steriade M, Timofeev I, Dürmüller N, Grenier F: Dynamic properties of corticothalamic neurons and local cortical interneurons generating fast rhythmic $(30-40 \mathrm{~Hz})$ spike bursts. J Neurophysiol 79:483-490, 1998

34. Tasker RR, Davis KD, Hutchison WD, Dostrovsky JO: Subcortical and thalamic mapping in functional neurosurgery, in Gildenberg PL, Tasker RR (eds): Textbook of Stereotactic and Functional Neurosurgery. New York: McGraw-Hill, 1998, pp 883-909

35. Tóth TI, Crunelli V: Simulation of intermittent action potential firing in thalamocortical neurons. Neuroreport 8:28892892,1997

36. van der Loo E, Gais S, Congedo M, Vanneste S, Plazier M, Menovsky T, et al: Tinnitus intensity dependent gamma oscillations of the contralateral auditory cortex. PLoS One 4:e7396, 2009

37. von der Malsburg C: The Correlation Theory of Brain Function. Internal Report 81-2. Göttingen: Max-PlanckInstitute for Biophysical Chemistry, 1981

38. Weinberger M, Hutchison WD, Lozano AM, Hodaie M, Dostrovsky JO: Increased gamma oscillatory activity in the subthalamic nucleus during tremor in Parkinson's disease patients. J Neurophysiol 101:789-802, 2009
39. Yamamoto T, Katayama Y, Obuchi T, Kano T, Kobayashi K, Oshima $\mathrm{H}$, et al: Thalamic sensory relay nucleus stimulation for the treatment of peripheral deafferentation pain. Stereotact Funct Neurosurg 84:180-183, 2006

40. Zhan XJ, Cox CL, Sherman SM: Dendritic depolarization efficiently attenuates low-threshold calcium spikes in thalamic relay cells. J Neurosci 20:3909-3914, 2000

\section{Disclosures}

Diellor Basha, Dr. Hutchison, and Dr. Lozano report receiving grants, and/or travel funds, and/or lecture honoraria from Medtronic. Dr. Lozano reports being a consultant for Medtronic, St. Jude, and Boston Scientific.

\section{Author Contributions}

Conception and design: Basha. Acquisition of data: Hutchison, Kalia, Hodaie, Lozano. Analysis and interpretation of data: Hutchison, Basha, Dostrovsky. Drafting the article: Basha. Critically revising the article: Hutchison, Basha, Dostrovsky, Lozano. Reviewed submitted version of manuscript: Hutchison, Dostrovsky, Kalia, Hodaie, Lozano. Statistical analysis: Basha. Administrative/technical/material support: Hutchison. Study supervision: Hutchison.

\section{Supplemental Information \\ Previous Presentations}

Portions of this work were presented in poster form as proceedings at Neuroscience 2013, the annual meeting of the Society for Neuroscience, in San Diego, California, November 9-12, 2013.

\section{Correspondence}

William D. Hutchison, Division of Neurosurgery, Toronto Western Hospital, 399 Bathurst St., MP11-308, Toronto, ON M5S 2T8, Canada.email: whutch@uhnres.utoronto.ca. 